\title{
Course Planning in Educational Programs: A Project Management Approach
}

\author{
Manohar S. Madan \\ Information Technology and Supply Chain Management Department, \\ University of Wisconsin-Whitewater, Whitewater, Wisconsin, USA \\ E-mail: madanm@uww.edu (Corresponding Author) \\ Kingsley Gnanendran \\ Operations and Information Management Department, \\ University of Scranton, Scranton, Pennsylvania, USA \\ E-mail: skingsley.gnanendran@scranton.edu
}

\begin{abstract}
Universities today face heightened competition, tight budgets, and stringent accreditation requirements. Students, on the other hand, have expectations in terms of time-to-degree, cost of attendance, program quality, curricular flexibility, and schedule convenience. Researchers have used various approaches to address educational program planning: mathematical programming, simulation, Markov analysis, material requirements planning, and flow analysis. Here, we propose a data-driven approach that uses enrollment data along with project management methodology. The degree program is viewed as a "project" with multiple, related tasks (courses). We define appropriate performance measures and develop decision rules to determine the schedule for future course offerings.
\end{abstract}

Keywords: project management, multi-project scheduling, course planning, educational management, value co-creation

\section{INTRODUCTION}

A common definition of project is that it is a series of related tasks directed toward a significant outcome and requiring a substantial amount of time to complete (Jacobs and Chase, 2018). In that sense, an educational program such as an undergraduate or graduate degree program, may be viewed as a project requiring completion of a set of related tasks (i.e. courses). Each task has a specific duration (e.g. a semester) and each task may have precedence requirements (e.g. prerequisites for the course). The client for this project is any student enrolled in such a program. The student essentially "contracts" with the educational institution to enroll in courses required to complete the program and earn the degree. In return, the educational institution is expected to offer and facilitate a prescribed set of courses in the appropriate sequence and timing in order that the student may progress toward graduation in an efficient manner. Given the large number of students that may matriculate into a specific program at any particular time, the institution needs to manage myriad individual degree pathways. Instead, by considering groups of students according to when they entered the program ("cohort"), the institution's task becomes one of managing the progress of each group (cohort) with the objective of minimizing the average time- to-degree across the cohort while meeting project criteria such as cost, quality, and flexibility that are important to the student as well as the institution. In other words, the institution's task can be viewed as managing programs consisting of multiple simultaneous projects involving a variety of criteria.

Project management is defined as the planning, directing, and controlling of resources to meet the technical, cost, and time constraints of the project (Jacobs and Chase, 2018). In this research, we propose a project approach to managing educational programs that takes into account not only strategic concerns, but also operational nuances that are unique to the educational sector. Educational projects as defined in this research are quite different from conventional projects such as those found in engineering construction or computer software development. In the educational context, the client's (student's) participation goes well beyond financial commitment. Value is co-created by the student and the educational institution. According to the value cocreation perspective (Prahalad and Ramaswamy, 2004), in addition to the business, the consumer or user also contributes to creating value. Completing courses and navigating a path to degree completion requires active collaboration of student and institution through the academic advising process. Responsibility for project performance therefore falls on both parties: the student must be enrolled in the right courses at the right times; while the institution, for its part, must ensure that the right courses are offered at the right times. In addition, an enrolled student must satisfy course requirements (assignments, etc.) to pass the course. Educational institutions are increasingly coming under financial pressure, and must work within resource constraints such as qualified faculty (accreditation guidelines), space (section size), and time (schedule conflict). Even though each entering student implicitly commits to completing the degree, the ultimate responsibility for actually taking and passing courses rests exclusively with the student. Hence, a student choosing to delay or slow down their participation in the program has a direct impact on the performance metrics (cost, time) of the educational institution.

In the educational context, it is imperative that student and institution work together collaboratively to enable the 
former to navigate an efficient pathway toward degree attainment. In addition, there is a need to define appropriate performance measures that capture the nuances and subtleties of the education sector. The nuances of the education sector are exemplified in the definitions proposed in this research for measuring program performance related to progress towards targets of time and costs.

The objectives of educational institutions go beyond consideration of the traditional project criteria, namely the iron triangle (Atkinson, 1999) of cost, time, and quality of the offered programs. They also need to consider process benefits such as organizational efficiency and effectiveness when assessing project performance. In that sense, these perspectives in managing educational programs "fit" Atkinson's square route approach (Atkinson, 1999) to evaluating project success. At the level of the college (e.g. a college of business), the primary objective could be one of minimizing the expected number of terms needed to graduate (time-to-degree) across a college-wide entering class that began the program at a particular point (term) in time. A secondary objective might be the maximization of resource utilization (such as instructional faculty and computer laboratories). At a departmental level (e.g. marketing department) that offers only discipline-specific courses, the objectives of time-to-degree and utilization of resources may be prioritized differently. At this level, the overriding objective would likely be one of maximizing the utilization of the department's internal resources. Within the institution therefore, the motivating objective could vary with the level of the particular entity in the overall hierarchy.

In this research, we model educational programs using project management methodology. We develop unique performance measures of schedule and cost for educational programs. Based on different performance measures, we provide guidelines to determine course offerings for a future term. The rest of this paper is organized as follows: we begin with a review of the literature in $\$ 2$, followed by a description of the proposed approach in $\S 3$. Our methodology is described and illustrated with a numerical example in $\S 4$. The results are discussed in $\$ 5$, followed by concluding comments in $\S 6$.

\section{LITERATURE REVIEW}

In this section, we review literature pertaining to two areas relevant to our research: educational program planning, and management of multiple projects. There are different methodological approaches for course/program planning in the literature. In an extensive review of operations research (OR) applications in the education sector, Johnes (2015) classifies the literature into categories such as planning, resource allocation, scheduling, and performance measurement. Johnes (2015) also notes the presence of competing and often conflicting objectives in education planning and performance measurement and therefore the need for multiple-criteria decision analysis.

Besent and Besent (1980) and Kwak et al. (1986) model educational program using the Markov chain framework. Boronico (2000) presents a quantitative model for course scheduling. Dyson (2000) discusses the role of OR in linking strategy and performance measurements, and presents a model that shows performance measurement as an important component of strategy development. Mayston
(2003) discusses the importance of performance evaluation in managing educational systems. Litteral and Walk (2010) present an approach based on Little's Law (Little, 1961) to manage enrollment in part-time degree programs. Saltzman and Roeder (2012) use a simulation approach to analyze student flow in a college of business. Cox and Jesse (1981) adapted the well-known material requirements planning (MRP) technique from manufacturing management to higher education planning. Gnanendran (2016) used linear programming to further refine the approach of Cox and Jesse (1981) and apply it to the course cycling problem in parttime, online degree programs. Nasholm and Blomquist (2015) present a case-based study of value co-creation as a strategy for educational program management. We wish to emphasize here that there is no research reported of the use or application of project management approach to education program planning.

With regard to literature relevant to managing multiple projects, Payne (2007) presents a review of research on management of multiple simultaneous projects. Payne (2007) discusses projects in environments where multiprojects are smaller than single projects and shorter in duration. In a detailed survey of project scheduling, Herroelen (2005) notes that a common approach in multiproject settings is to develop heuristics that treat the individual projects as independent. Kurtulus and Davis (1982) discuss different heuristic rules for scheduling in the multi-project environment. Kurtulus (1985) and Kurtulus and Narula (1985) discuss analysis of project performance under different priority rules used for scheduling in a constrained multiple-project environment. Lova et al. (2000) present a multi-criteria heuristic to allocate resources in multi-project scheduling. Kavadias and Loch (2003) discuss project sequencing as well as prioritization policy for resource allocation in a multi-project environment.

\section{PROBLEM DESCRIPTION AND METHODOLOGY}

An important problem faced by degree program administrators is the identification of an appropriate mix of courses and course sections to offer in upcoming terms so that students can progress to degree efficiently within the constraints of limited institutional resources. In this research, we model this problem using the project approach. We treat an entire cohort of students (that is, those matriculating at the same point in time) as a single "project" to be managed by the institution. Although this would be more coarse-grained than a "one student to one project" view, our approach yields a more manageable methodology in terms of the data collection and processing requirements. Since multiple cohorts are simultaneously active in the program, this approach results in the multi-project environment alluded to previously. Likewise, we also treat the degree program as comprising a set of coarse-grained components (core, electives, etc.) rather than addressing it at the level of individual courses. In this sense, our methodology is analogous to the well-known aggregate planning technique from the operations management literature.

We begin by defining measures of project performance, such as earned value, planned value, and actual cost 
specifically in the educational context. The following are the required data inputs to the model:
$i, j, k$
index for cohort, term, and program component (respectively)

CAP maximum capacity, in number of students, of a (course) section

EC expected course load per student per term

$N D \quad$ number of courses required for degree

ID ideal duration (number of terms), computed as $I D=N D / E C$

$N C \quad$ expected number of contemporaneous cohorts

COMP cost (e.g. instructor compensation) per section taught

$\operatorname{NSEC}(k, j)$ number of sections from program component $k$ offered in term $j$

$\operatorname{TSEC}(j) \quad$ total number of sections offered in term $j$

$\operatorname{OFF}(i, j) \quad$ number of sections apportioned to cohort $i$ in term $j$

$\operatorname{SIZE}(i)$ number of students in cohort $i$ (those entering in term $i$ )

$\operatorname{ENR}(i, j) \quad$ number of course enrollments by cohort $i$ in $\operatorname{term} j$

Additionally we need the following notation to capture project performance (measured in number of courses):

\begin{tabular}{|c|c|}
\hline$E V(i, j)$ & $\begin{array}{l}\text { earned value per student for cohort } i \text { in term } \\
j\end{array}$ \\
\hline$P V(i, j)$ & $\begin{array}{l}\text { planned value per student for cohort } i \text { in } \\
\text { term } j\end{array}$ \\
\hline$A C(i, j)$ & actual cost per student for cohort $i$ in term $j$ \\
\hline$C E V(i, j)$ & $\begin{array}{l}\text { cumulative earned value per student for } \\
\text { cohort } i \text { in term } j\end{array}$ \\
\hline$C P V(i, j)$ & $\begin{array}{l}\text { cumulative planned value per student for } \\
\text { cohort } i \text { in term } j\end{array}$ \\
\hline$C A C(i, j)$ & $\begin{array}{l}\text { cumulative actual cost per student for } \\
\text { cohort } i \text { in term } j\end{array}$ \\
\hline$S P I(i, j)$ & $\begin{array}{l}\text { schedule performance index for cohort } i \text { in } \\
\text { term } j\end{array}$ \\
\hline$C P I(i, j)$ & $\begin{array}{l}\text { cost performance index for cohort } i \text { in term } \\
j\end{array}$ \\
\hline
\end{tabular}

With these notations, we can now define the per-student planned value, earned value, and actual cost (in course units) for each cohort-term combination. Planned Value $(P V)$ is an institution's expectation of the number of courses that will be completed by a student in a term. In that sense, $P V$ can be considered as project baseline. In our problem, $P V$ is equal to $E C$ (expected course load per student per term). Earned Value is the value of work performed, i.e. the average number of courses completed by a student in a term. Actual Cost $(A C)$ is the average cost of work performed, i.e. courses offered in a term by the institution. Cohort $i$ enters in term $i$, so for $j \geq i$ :

$E V(i, j)=\frac{E N R(i, j)}{\operatorname{SIZE}(i)}$

$P V(i, j)=E C$

The total number of sections offered in term $j$, $\operatorname{TSEC}(j)$, is apportioned among the various cohorts as
$O F F(i, j)$, based on the program component(s) that each cohort would typically take in the given term. Detailed explanation of the apportionment process is provided in the next section. The per-student actual cost (in course units) for each cohort-term combination can then be defined, again for $j \geq i$ :

$A C(i, j)=\frac{O F F(i, j) \times C A P}{\operatorname{SIZE}(i)}$

Cumulatively:

$\operatorname{CEV}(i, j)=\sum_{m=i}^{j} E V(i, m)$
$\operatorname{CPV}(i, j)=\sum_{m=i}^{j} P V(i, m)$
$\operatorname{CAC}(i, j)=\sum_{m=i}^{j} A C(i, m)$

Schedule and cost performance indices are defined as (for $j \geq i)$ :

$\operatorname{SPI}(i, j)=\frac{\operatorname{CEV}(i, j)}{\operatorname{CPV}(i, j)}$
$\operatorname{CPI}(i, j)=\frac{\operatorname{CEV}(i, j)}{\operatorname{CAC}(i, j)}$

Note that schedule and cost performance indices are similar to conventional projects. However, $E V, P V$, and $A C$ used to compute the performance indices are in course units.

The structure of the problem discussed in this research is different from projects in most multi-project environments. As stated earlier, we consider an entire cohort of students (in a program) starting in a particular term as a single "project" to be managed by the institution. However, projects in different cohorts in the same program are quite similar in nature. Start times for all projects (i.e. cohorts) is beginning of a term. Planned value is same for each cohort. The number of activities (courses) needed to complete a project is same. Finally, all tasks (courses) have the same duration (one term). Given the unique structure of projects, we define additional measures of performance shown below. We carry out the following series of calculations on each cohort $(i)$ for the most recent completed term, $\mathrm{J}$.

Projected duration:

$P D(i, J)=I D / S P I(i, J)$

$P D$ is projected duration for cohort $i$ based on the schedule efficiency at term $J$.

Projected schedule delay:

$P S D(i, J)=P D(i, J)-I D$

$P S D$ is the schedule delay for cohort $i$ based on the schedule efficiency at term $J$.

Remaining enrollments:

$\underset{\text { Remaining }}{\text { Enrollments }(i, J)}=(\operatorname{SIZE}(i) \times N D)-\sum_{j=1}^{J} \operatorname{ENR}(i, j)(11)$ This is the projected demand for course enrollments attributable to cohort $i$ for the remainder of their program.

Minimum time to completion from term $(J+1)$ onward:

$\operatorname{MTC}(i, J)=$

RemainingEnrollments $(i, J) /(\operatorname{SIZE}(i) \times E L)$

$M T C$ is a lower bound on the time cohort $i$ needs to complete the remainder of their program. 
Minimum duration:

$M D(i, J)=(N C-i+1)+\operatorname{MTC}(i, J)$

$M D$ is a lower bound on the overall "time-to-degree" for cohort $i$.

Minimum schedule delay:

$M S D(i, J)=M D(i, J)-I D$

$M S D$ is a lower bound on the schedule delay for cohort $i$, projected at term $J$.

Baseline cost:

BaselineCost $(i)=\frac{\operatorname{SIZE}(i) \times N D \times \operatorname{COMP}}{C A P}$

BaselineCost is a lower bound on the cost of program completion for cohort $i$.

Projected cost:

ProjectedCost $(i, J)=$ BaselineCost $(i) / C P I(i, J)$

ProjectedCost is the cost of the program for cohort $i$ based on its cost efficiency at term $\mathrm{J}$.

Projected cost overrun:

$\operatorname{PCO}(i, J)=\operatorname{ProjectedCost}(i, J)-$ BaselineCost $(i) \quad(17)$ $P C O$ is the program cost overrun for cohort $i$ based on its cost efficiency at term $\mathrm{J}$.

Given an institution's policy and resource constraints, future course offerings could now be guided by using the above measures. Next, we illustrate this method via a numerical example.

\section{ILLUSTRATIVE EXAMPLE}

We use the example of an MBA program offered by a small, private university in the Northeastern region of USA. The structure of the program is depicted in Figure 1 as a "bill of courses" akin to the "bill of materials" concept used in material requirements planning (MRP). Courses in the program belong to one of four "components": a gateway course (cornerstone), a core comprising three clusters of courses, several elective courses, and a final capstone course. Once any mandated remedial courses (called "foundation modules") are completed by the student, the "main program" requires successful completion of twelve courses, or 36 credits: a cornerstone course (CR), four core courses chosen from three clusters in the areas of Accounting, Economics, or Finance (AEF cluster), Management or Marketing (MM cluster), and Operations or Information Management (OI cluster), six elective courses (EL), and a final capstone course (CP). Our focus in this paper is on the main program only, after students have completed any necessary remedial courses.

An academic year consists of three terms: fall, spring, and summer. With an average course load of two courses per term, the expected time-to-degree in this program (the ideal duration, $I D$ ) is six terms, or two years if the student enrolls in summer terms as well. It should be noted that this is not a "lockstep" program, and some students take significantly longer than two years to complete due to any number of reasons, such as family commitments, workplace demands, financial issues, or academic difficulties. Therefore, there would be more than six cohorts active in the program at any point in time, e.g. students admitted seven or more terms ago but are yet to complete. Although a few highly-motivated students may be able to complete the program in less than 2 years, the expected number of active cohorts at any point in time is six. In our analysis, we identify and examine the six most recently admitted cohorts as the "active" cohorts.

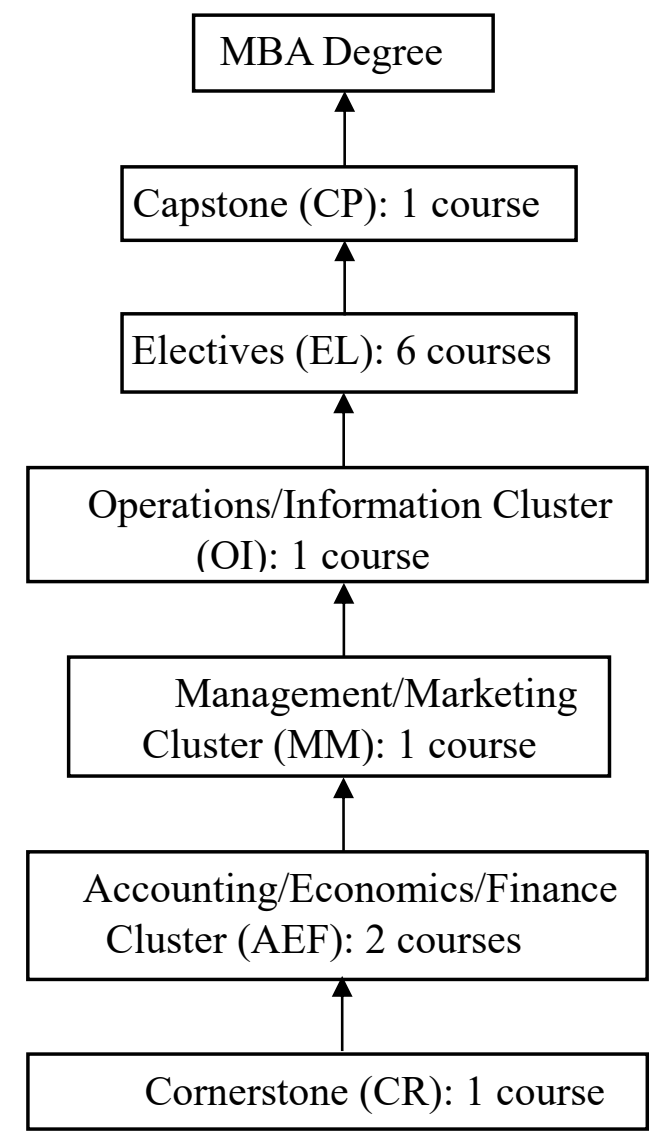

Figure 1 Program structure

Students typically take and complete courses in the following sequence:

First term: CR, AEF

Second term: AEF, MM

Third term: OI, EL

Fourth term: EL, EL

Fifth term: EL, EL

Sixth term: EL, CP

Figure 2 depicts the progress of each cohort of students at a given point in time (say Term 6). The shaded cells indicate completed courses, with Cohort 1 having begun six terms ago, Cohort 2 five terms ago, and so on. 


\begin{tabular}{|c|c|c|c|c|c|c|c|c|c|c|c|c|}
\hline 冫 & \multicolumn{12}{|c|}{ Term in Program } \\
\hline & \multicolumn{2}{|c|}{1} & \multicolumn{2}{|c|}{2} & \multicolumn{2}{|c|}{3} & \multicolumn{2}{|c|}{4} & \multicolumn{2}{|c|}{5} & \multicolumn{2}{|c|}{6} \\
\hline Course & $\mathrm{CR}$ & $\mathrm{AEF}$ & $\mathrm{AEF}$ & MM & $\mathrm{OI}$ & $\mathrm{EL}$ & $\mathrm{EL}$ & $\mathrm{EL}$ & $\mathrm{EL}$ & $\mathrm{EL}$ & EL & $\mathrm{CP}$ \\
\hline Cohort 1 & & & & & & & & & & & & \\
\hline Cohort 2 & & & & & & & & & & & & \\
\hline Cohort 3 & & & & & & & & & & & & \\
\hline Cohort 4 & & & & & & & & & & & & \\
\hline Cohort 5 & & & & & & & & & & & & \\
\hline Cohort 6 & & & & & & & & & & & & \\
\hline
\end{tabular}

Figure 2 Cohort progression

\subsection{Data}

The following sample data is used to illustrate our methodology.

Maximum permitted capacity of a course : 20 students section $(C A P)$

Expected course load per term per student : 2 courses $(E C)$

Number of courses required for degree $(N D): 12$ courses Ideal program duration

$(I D)=N D / E C=12 / 2$

Expected number of contemporaneous : 6 cohorts cohorts $(N C)$

Cost (e.g. instructor compensation) per : $\$ 10,000$ course section taught $(C O M P)$

Table 1 indicates the number of course sections offered by the institution in each of the past six terms broken down by program component.

Table 1 Course sections offered by program component and term, $\underline{N S E C}(k, j)$

\begin{tabular}{cccccccc}
\hline \multicolumn{7}{c}{ Term } & Total \\
\cline { 1 - 6 } $\begin{array}{c}\text { Program } \\
\text { Component }\end{array}$ & $\mathbf{1}$ & $\mathbf{2}$ & $\mathbf{3}$ & $\mathbf{4}$ & $\mathbf{5}$ & $\mathbf{6}$ & \\
\hline $\boldsymbol{C P}$ & 1 & 2 & 1 & 2 & 2 & 1 & 9 \\
\hline EL & 10 & 9 & 10 & 10 & 10 & 11 & 60 \\
\hline OI & 1 & 2 & 2 & 3 & 3 & 3 & 14 \\
\hline $\boldsymbol{M M}$ & 2 & 2 & 3 & 2 & 3 & 2 & 14 \\
\hline $\boldsymbol{A E F}$ & 3 & 4 & 4 & 4 & 4 & 3 & 22 \\
\hline $\boldsymbol{C R}$ & 2 & 2 & 2 & 1 & 2 & 2 & 11 \\
\hline $\boldsymbol{T S E C}(\boldsymbol{j})$ & 19 & 21 & 22 & 22 & 24 & 22 & 130 \\
\hline
\end{tabular}

Table 2 indicates the number of course sections attributable to each cohort-term combination.

For the purpose of this study, we shall identify each cohort by a serial number denoting the term in which they matriculated, measured from some arbitrary point in time (say 1/1/2017). Thus, Cohort 1 started in Term 1 (Spring 2017), Cohort 3 would start in Term 3 (Fall 2017), while Cohort -3 would have started 3 terms prior to $1 / 1 / 2017$, i.e. Spring 2016.
Table 2 Sections attributable to each cohort-term combination, $\operatorname{OFF}(i, j)$

\begin{tabular}{|c|c|c|c|c|c|c|c|}
\hline \multirow[b]{2}{*}{ Cohort } & \multicolumn{6}{|c|}{ Term } & \multirow{2}{*}{$\begin{array}{c}\text { Cohort } \\
\text { in } \\
\text { Lower } \\
\text { Triangle }\end{array}$} \\
\hline & 1 & 2 & 3 & 4 & 5 & 6 & \\
\hline 1 & 3.5 & 4 & 3.67 & 3.33 & 3.33 & 2.83 & -- \\
\hline 2 & 2.67 & 4 & 5 & 4.67 & 3.33 & 3.67 & -5 \\
\hline 3 & 3.33 & 3.5 & 4 & 4 & 4.67 & 3.67 & -4 \\
\hline 4 & 3.33 & 3 & 2.67 & 3 & 5 & 4.83 & -3 \\
\hline 5 & 2.67 & 3 & 3.33 & 3.67 & 4 & 3.5 & -2 \\
\hline 6 & 3.5 & 3.5 & 3.33 & 3.33 & 3.67 & 3.5 & -1 \\
\hline Total & 19 & 21 & 22 & 22 & 24 & 22 & 130 \\
\hline
\end{tabular}

To explain the apportionment method, we look at how the figure for Cohort 1 in Term 3 (3.67 above) was computed: 22 course sections were offered in Term 3 , broken down as: $1 \mathrm{CP}, 10 \mathrm{EL}, 2 \mathrm{OI}, 3 \mathrm{MM}, 4 \mathrm{AEF}$, and $2 \mathrm{CR}$ (see Table 1). In Term 3, the following cohorts are active: 1, 2, 3 (in the upper triangle), and $-3,-2$, and -1 (in the lower triangle). These six cohorts are at various stages of progress through the program as shown below:

Cohort 1, Term 3: in third term of its progress, takes OI and EL

Cohort 2, Term 3: in second term of its progress, takes AEF and MM

Cohort 3, Term 3: in first term of its progress, takes CR and AEF

Cohort -3 , Term 3: in sixth term of its progress, takes EL and $\mathrm{CP}$

Cohort -2, Term 3: in fifth term of its progress, takes EL and EL

Cohort -1, Term 3: in fourth term of its progress, takes EL and EL

Note that the OI courses are taken exclusively by our cohort (Cohort 1) whereas the EL courses are shared among Cohorts $1,-3,-2$, and -1 . Moreover, Cohort 1 and -3 take EL courses along with another component (OI and $\mathrm{CP}$ respectively) whereas Cohorts -2 and -1 take EL courses exclusively. Therefore EL course sections in Term 3 are allocated as follows: 1/6 share each to Cohorts 1 and -3 , and $1 / 3$ share each to Cohorts -2 and -1 . Thus the number of 
course sections attributable to Cohort 1 in Term 3 is all of the offered OI sections plus a $(1 / 6)^{\text {th }}$ share of the EL sections. This yields: $2+(1 / 6) 10=3.67$ sections. The rest of the numbers in the Table 2 were generated using similar logic which is summarized in the following table (Table 3 ).

Table 3 Apportionment method

\begin{tabular}{|c|c|c|c|c|c|c|}
\hline & \multicolumn{6}{|c|}{ Term } \\
\hline Cohort & 1 & 2 & 3 & 4 & 5 & 6 \\
\hline 1 & $\mathrm{CR}+(1 / 2) \mathrm{AEF}$ & $\mathrm{MM}+(1 / 2) \mathrm{AEF}$ & $\mathrm{OI}+(1 / 6) \mathrm{EL}$ & $(1 / 3) E L$ & (1/3)EL & $\mathrm{CP}+(1 / 6) \mathrm{EL}$ \\
\hline 2 & $\mathrm{CP}+(1 / 6) \mathrm{EL}$ & $C R+(1 / 2) A E F$ & $\mathrm{MM}+(1 / 2) \mathrm{AEF}$ & $\mathrm{OI}+(1 / 6) \mathrm{EL}$ & (1/3)EL & $(1 / 3) E L$ \\
\hline 3 & $(1 / 3) \mathrm{EL}$ & $\mathrm{CP}+(1 / 6) \mathrm{EL}$ & $C R+(1 / 2) A E F$ & $\mathrm{MM}+(1 / 2) \mathrm{AEF}$ & $\mathrm{OI}+(1 / 6) \mathrm{EL}$ & $(1 / 3) E L$ \\
\hline 4 & (1/3)EL & (1/3)EL & $\mathrm{CP}+(1 / 6) \mathrm{EL}$ & $\mathrm{CR}+(1 / 2) \mathrm{AEF}$ & $\mathrm{MM}+(1 / 2) \mathrm{AEF}$ & $\mathrm{OI}+(1 / 6) \mathrm{EL}$ \\
\hline 5 & $\mathrm{OI}+(1 / 6) \mathrm{EL}$ & $(1 / 3) E L$ & $(1 / 3) E L$ & $\mathrm{CP}+(1 / 6) \mathrm{EL}$ & $C R+(1 / 2) A E F$ & $\mathrm{MM}+(1 / 2) \mathrm{AEF}$ \\
\hline 6 & $\mathrm{MM}+(1 / 2) \mathrm{AEF}$ & $\mathrm{OI}+(1 / 6) \mathrm{EL}$ & (1/3)EL & (1/3)EL & $\mathrm{CP}+(1 / 6) \mathrm{EL}$ & $\mathrm{CR}+(1 / 2) \mathrm{AEF}$ \\
\hline
\end{tabular}

Table 4 represents hypothetical sample data on the size of the last six cohorts, and the number of course enrollments completed over the past six terms by the members of these cohorts. Thus, the 42 students belonging to Cohort 1 completed 58, 51, 67, 64, 44, and 35 courses during the past six terms. Similarly, the 43 students in Cohort 2 (who would have started the program in Term 2), completed 26, 75, 32, 66 , and 22 courses in the past five terms.

Table 4 Enrollments completed in each term, $\operatorname{ENR}(i, j)$

\begin{tabular}{ccccccccc} 
& \multicolumn{7}{c}{ Term } & Total \\
\cline { 1 - 6 } Cohort & $\boldsymbol{S I Z E}(\boldsymbol{i})$ & $\mathbf{1}$ & $\mathbf{2}$ & $\mathbf{3}$ & $\mathbf{4}$ & $\mathbf{5}$ & $\mathbf{6}$ & \\
\cline { 1 - 6 } $\mathbf{1}$ & 42 & 58 & 51 & 67 & 64 & 44 & 35 & 319 \\
\hline $\mathbf{2}$ & 43 & & 26 & 75 & 32 & 66 & 22 & 221 \\
\hline $\mathbf{3}$ & 41 & & & 33 & 39 & 79 & 69 & 220 \\
\hline $\mathbf{4}$ & 36 & & & & 57 & 57 & 34 & 148 \\
\hline $\mathbf{5}$ & 38 & & & & 38 & 41 & 79 \\
\hline $\mathbf{6}$ & 39 & & & & & 25 & 25 \\
\hline Total & 239 & & & & & & & 1012
\end{tabular}

\subsection{Analysis}

We begin the analysis by computing the term-by-term earned value $(E V)$ for the six cohorts examined, using eq. (1). These are shown in Table 5.

Table 5 Earned value, $E V(i, j)$

\begin{tabular}{ccccccc}
\multicolumn{7}{c}{ Term } \\
\hline Cohort & $\mathbf{1}$ & $\mathbf{2}$ & $\mathbf{3}$ & $\mathbf{4}$ & $\mathbf{5}$ & $\mathbf{6}$ \\
\hline $\mathbf{1}$ & 1.38 & 1.21 & 1.60 & 1.52 & 1.05 & 0.83 \\
\hline $\mathbf{2}$ & & 0.60 & 1.74 & 0.74 & 1.53 & 0.51 \\
\hline $\mathbf{3}$ & & & 0.80 & 0.95 & 1.93 & 1.68 \\
\hline $\mathbf{4}$ & & & & 1.58 & 1.58 & 0.94 \\
\hline $\mathbf{5}$ & & & & & 1.00 & 1.08 \\
\hline $\mathbf{6}$ & & & & & & 0.64 \\
\hline
\end{tabular}

As an example, $E V(1,3)$ was computed as: $\frac{\operatorname{ENR}(1,3)}{\operatorname{SIZE}(1)}=\frac{67}{42}=1.60$.

Next, the term-by-term planned value $(P V)$ is computed using eq. (2) and shown in Table 6. Note that these values are all equal to 2.00 since each student is expected to take two courses per term.
Table 6 Planned value, $P V(i, j)$

\section{Term}

\begin{tabular}{ccccccc}
\hline Cohort & $\mathbf{1}$ & $\mathbf{2}$ & $\mathbf{3}$ & $\mathbf{4}$ & $\mathbf{5}$ & $\mathbf{6}$ \\
\hline $\mathbf{1}$ & 2.00 & 2.00 & 2.00 & 2.00 & 2.00 & 2.00 \\
\hline $\mathbf{2}$ & & 2.00 & 2.00 & 2.00 & 2.00 & 2.00 \\
\hline $\mathbf{3}$ & & & 2.00 & 2.00 & 2.00 & 2.00 \\
\hline $\mathbf{4}$ & & & & 2.00 & 2.00 & 2.00 \\
\hline $\mathbf{5}$ & & & & & 2.00 & 2.00 \\
\hline $\mathbf{6}$ & & & & & & 2.00
\end{tabular}

Term-by-term actual costs are computed using eq. (3), and displayed in Table 7. As an example, $A C(1,3)$ was computed as:

$\frac{\operatorname{OFF}(1,3) \times C A P}{\operatorname{SIZE}(1)}=\frac{3.67 \times 20}{42}=1.75$.

Table 7 Actual cost, $A C(i, j)$

\begin{tabular}{ccccccc}
\multicolumn{7}{c}{ Term } \\
\hline Cohort & $\mathbf{1}$ & $\mathbf{2}$ & $\mathbf{3}$ & $\mathbf{4}$ & $\mathbf{5}$ & $\mathbf{6}$ \\
\hline $\mathbf{1}$ & 1.67 & 1.90 & 1.75 & 1.59 & 1.59 & 1.35 \\
\hline $\mathbf{2}$ & & 1.86 & 2.33 & 2.17 & 1.55 & 1.71 \\
\hline $\mathbf{3}$ & & 1.95 & 1.95 & 2.28 & 1.79 \\
\hline $\mathbf{4}$ & & & 1.67 & 2.78 & 2.69 \\
\hline $\mathbf{5}$ & & & & 2.11 & 1.84 \\
\hline $\mathbf{6}$ & & & & & 1.79 \\
\hline
\end{tabular}

The cumulative earned values, planned values, and actual costs, computed using eqs. (4) - (6) are displayed in Tables 8 through 10.

Table 8 Cumulative earned value, $C E V(i, j)$

\begin{tabular}{ccccccc}
\multicolumn{7}{c}{ Term } \\
\hline Cohort & $\mathbf{1}$ & $\mathbf{2}$ & $\mathbf{3}$ & $\mathbf{4}$ & $\mathbf{5}$ & $\mathbf{6}$ \\
\hline $\mathbf{1}$ & 1.38 & 2.60 & 4.19 & 5.71 & 6.76 & 7.60 \\
\hline $\mathbf{2}$ & & 0.60 & 2.35 & 3.09 & 4.63 & 5.14 \\
\hline $\mathbf{3}$ & & & 0.80 & 1.76 & 3.68 & 5.37 \\
\hline $\mathbf{4}$ & & & 1.58 & 3.17 & 4.11 \\
\hline $\mathbf{5}$ & & & & 1.00 & 2.08 \\
\hline $\mathbf{6}$ & & & & & 0.64 \\
\hline
\end{tabular}


Table 9 Cumulative planned value, $C P V(i, j)$

$$
\text { Term }
$$

\begin{tabular}{ccccccc}
\hline Cohort & $\mathbf{1}$ & $\mathbf{2}$ & $\mathbf{3}$ & $\mathbf{4}$ & $\mathbf{5}$ & $\mathbf{6}$ \\
\hline $\mathbf{1}$ & 2.00 & 4.00 & 6.00 & 8.00 & 10.00 & 12.00 \\
\hline $\mathbf{2}$ & & 2.00 & 4.00 & 6.00 & 8.00 & 10.00 \\
\hline $\mathbf{3}$ & & & 2.00 & 4.00 & 6.00 & 8.00 \\
\hline $\mathbf{4}$ & & & & 2.00 & 4.00 & 6.00 \\
\hline $\mathbf{5}$ & & & & & 2.00 & 4.00 \\
\hline $\mathbf{6}$ & & & & & & 2.00 \\
\hline
\end{tabular}

Table 10 Cumulative actual cost, $C A C(i, j)$

\begin{tabular}{ccccccc}
\multicolumn{7}{c}{ Term } \\
\hline Cohort & $\mathbf{1}$ & $\mathbf{2}$ & $\mathbf{3}$ & $\mathbf{4}$ & $\mathbf{5}$ & $\mathbf{6}$ \\
\hline $\mathbf{1}$ & 1.67 & 3.57 & 5.32 & 6.90 & 8.49 & 9.84 \\
\hline $\mathbf{2}$ & & 1.86 & 4.19 & 6.36 & 7.91 & 9.61 \\
\hline $\mathbf{3}$ & & & 1.95 & 3.90 & 6.18 & 7.97 \\
\hline $\mathbf{4}$ & & & 1.67 & 4.44 & 7.13 \\
\hline $\mathbf{5}$ & & & & 2.11 & 3.95 \\
\hline $\mathbf{6}$ & & & & & 1.79 \\
\hline
\end{tabular}

Graphical representations of the cumulative earned values, planned values, and actual costs for Cohort 1 are shown in Figure 3.

\section{Cumulative EV, PV, and AC for Cohort 1}

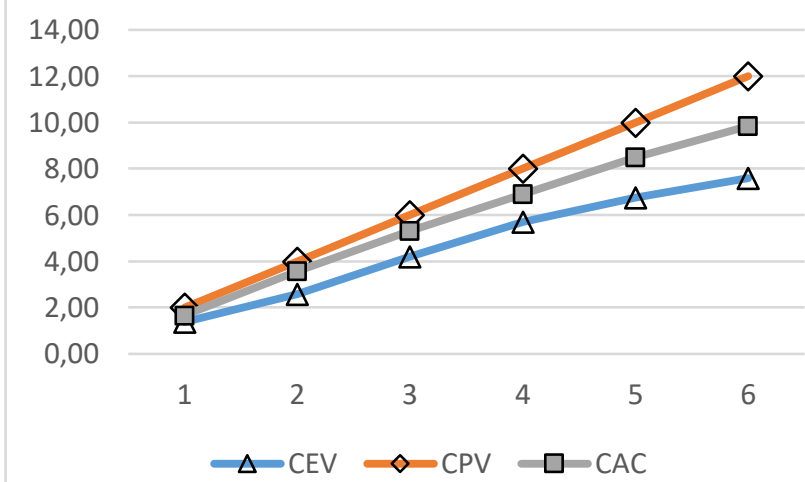

Figure 3 Cumulative earned and planned value, and cumulative actual cost for cohort 1

The schedule performance index and cost performance index computed using eqs. (7) - (8), are shown in Tables 11 and 12.

Table 11 Schedule performance index, $\operatorname{SPI}(i, j)$

\begin{tabular}{ccccccc}
\multicolumn{7}{c}{ Term } \\
\hline Cohort & $\mathbf{1}$ & $\mathbf{2}$ & $\mathbf{3}$ & $\mathbf{4}$ & $\mathbf{5}$ & $\mathbf{6}$ \\
\hline $\mathbf{1}$ & 0.69 & 0.65 & 0.70 & 0.71 & 0.68 & 0.63 \\
\hline $\mathbf{2}$ & & 0.30 & 0.59 & 0.52 & 0.58 & 0.51 \\
\hline $\mathbf{3}$ & & & 0.40 & 0.44 & 0.61 & 0.67 \\
\hline $\mathbf{4}$ & & & & 0.79 & 0.79 & 0.69 \\
\hline $\mathbf{5}$ & & & & & 0.50 & 0.52 \\
\hline $\mathbf{6}$ & & & & & & 0.32 \\
\hline
\end{tabular}

Table 12 Cost performance index, $C P I(i, j)$

\section{Term}

\begin{tabular}{ccccccc}
\hline Cohort & $\mathbf{1}$ & $\mathbf{2}$ & $\mathbf{3}$ & $\mathbf{4}$ & $\mathbf{5}$ & $\mathbf{6}$ \\
\hline $\mathbf{1}$ & 0.83 & 0.73 & 0.79 & 0.83 & 0.80 & 0.77 \\
\hline $\mathbf{2}$ & & 0.33 & 0.56 & 0.49 & 0.59 & 0.53 \\
\hline $\mathbf{3}$ & & & 0.41 & 0.45 & 0.60 & 0.67 \\
\hline $\mathbf{4}$ & & & & 0.95 & 0.71 & 0.58 \\
\hline $\mathbf{5}$ & & & & & 0.48 & 0.53 \\
\hline $\mathbf{6}$ & & & & & & 0.36 \\
\hline
\end{tabular}

Graphical representations of schedule and cost performance indexes for Cohort 1 are shown in Figure 4.

\section{SPI and CPI for Cohort 1}

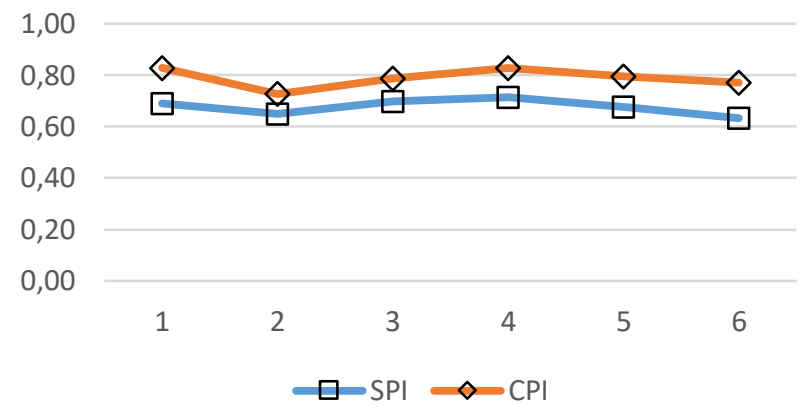

Figure 4 Schedule and cost performance indices for cohort 1

Next, additional performance measures using eqs. (9) to (17) are computed and are shown in Tables 13 through 15. Project status and minimum time to completion (MTC) are shown in Table 13. Projected schedule delay (PSD) is shown in Table 14. Projected cost overrun $(P C O)$ is shown in Table 15.

$\underline{\text { Table } 13 \text { Status of "projects" }}$

\begin{tabular}{ccccc}
\hline Cohort & $\begin{array}{c}\text { Cohort } \\
\text { Size }\end{array}$ & $\begin{array}{c}\text { Completed } \\
\text { Enrollments }\end{array}$ & $\begin{array}{c}\text { Remaining } \\
\text { Enrollments }\end{array}$ & $\begin{array}{c}\text { Minimum Time } \\
\text { to Completion } \\
\text { from here on } \\
\text { (MTC) }\end{array}$ \\
\hline $\mathbf{1}$ & 42 & 319 & 185 & 2.20 \\
\hline $\mathbf{2}$ & 43 & 221 & 295 & 3.43 \\
\hline $\mathbf{3}$ & 41 & 220 & 272 & 3.32 \\
\hline $\mathbf{4}$ & 36 & 148 & 284 & 3.94 \\
\hline $\mathbf{5}$ & 38 & 79 & 377 & 4.96 \\
\hline $\mathbf{6}$ & 39 & 25 & 443 & 5.68 \\
\hline
\end{tabular}

Table 14 Projections of schedule delay

\begin{tabular}{ccccc}
\hline Cohort & $\begin{array}{c}\text { Minimum } \\
\text { Duration } \\
(\text { MD) }\end{array}$ & $\begin{array}{c}\text { Projected } \\
\text { Duration } \\
(\text { PD) }\end{array}$ & $\begin{array}{c}\text { Minimum } \\
\text { Schedule } \\
\text { Delay } \\
\text { (MSD) }\end{array}$ & $\begin{array}{c}\text { Projected } \\
\text { Schedule } \\
\text { Delay } \\
(\text { PSD) }\end{array}$ \\
\hline $\mathbf{1}$ & 8.20 & 9.48 & 2.20 & 3.48 \\
\hline $\mathbf{2}$ & 8.43 & 11.67 & 2.43 & 5.67 \\
\hline $\mathbf{3}$ & 7.32 & 8.95 & 1.32 & 2.95 \\
\hline $\mathbf{4}$ & 6.94 & 8.76 & 0.94 & 2.76 \\
\hline $\mathbf{5}$ & 6.96 & 11.54 & 0.96 & 5.54 \\
\hline $\mathbf{6}$ & 6.68 & 18.72 & 0.68 & 12.72 \\
\hline
\end{tabular}


Table 15 Projections of cost overruns

\begin{tabular}{cccc} 
Cohort & Baseline Cost & Projected Cost & $\begin{array}{c}\text { Projected Cost } \\
\text { Overrun (PCO) }\end{array}$ \\
\hline $\mathbf{1}$ & $\$ 252,000$ & $\$ 326,520$ & $\$ 74,520$ \\
\hline $\mathbf{2}$ & $\$ 258,000$ & $\$ 482,534$ & $\$ 224,534$ \\
\hline $\mathbf{3}$ & $\$ 246,000$ & $\$ 365,273$ & $\$ 119,273$ \\
\hline $\mathbf{4}$ & $\$ 216,000$ & $\$ 374,595$ & $\$ 158,595$ \\
\hline $\mathbf{5}$ & $\$ 228,000$ & $\$ 432,911$ & $\$ 204,911$ \\
\hline $\mathbf{6}$ & $\$ 234,000$ & $\$ 655,200$ & $\$ 421,200$
\end{tabular}

\section{DISCUSSION}

From Eq. 1, we see that as course enrollments increase, $E V$ will correspondingly increase. As a result, SPI (Eq. 7) will improve and projected duration (Eq. 9) will decrease. Similarly, an increase in $E V$ also improves $C P I$ (Eq. 8) and decreases projected cost (Eq. 16). Actual enrollments in a term depend on the availability of a mix of courses appropriate to the various cohorts in progress. While we assume that students are motivated to take the expected number of courses every term (i.e. $P V$ ), actual enrollments also depend on students' resources (such as time and money) and external constraints (such as prerequisites and schedule).

Educational institutions face two overriding objectives in the planning and scheduling of courses: (i) minimize the average time-to-degree (time motivation); and (ii) maximize the utilization of resources (cost motivation). The two conflicting objectives can be addressed by adjusting course choice, i.e. the number and types of courses to be offered to students. To maximize the utilization of resources, an institution can offer fewer courses, deploying fewer instructors and improving cost efficiency. However such a plan would most likely result in an inadequate or inappropriate mix of courses for the cohorts in progress, resulting in a decrease in the number of enrollments, and thereby impacting schedule efficiency negatively. On the flip side, improving course choice will improve schedule efficiency at the expense of cost efficiency. (It should however be noted that a better schedule efficiency improves cash flow by enabling the collection of tuition revenue sooner.) Hence, it is necessary to explicitly consider the trade-off between choice and cost in course planning and scheduling.

A decision rule to select additions to the course offering plan for the upcoming term based on projected schedule delay ( $P S D$ in Table 14) is shown in Table 16. A cohort with a lower $P S D$ has a greater potential to avoid schedule slippage than a cohort with a higher $P S D$, and this observation is used to guide the addition of courses to the planned offerings for the upcoming term. Ignoring Cohort 1 (which will have exceeded its ideal duration in Term 7) the remaining cohorts are prioritized according to increasing schedule delay as: Cohort 4 - Cohort 3 - Cohort 5 - Cohort 2 - Cohort 6. Then, based on Figure 2, courses for addition to the next term $(\mathrm{J}+1)$ should be considered in the following order of program components: EL (for Cohort 4); EL (for Cohort 3); OI, EL (for Cohort 5); EL, CP (for Cohort 2); AEF, MM (for Cohort 6). Note that an alternative approach would have been to use the minimum schedule delay (MSD in Table 14 to prioritize the cohorts.
Table 16 Prioritizing cohorts (based on PSD) for course additions in upcoming term

\begin{tabular}{cccc}
\hline Cohort & $\begin{array}{c}\text { Projected } \\
\text { Schedule Delay } \\
(P S D)\end{array}$ & $\begin{array}{c}\text { Candidates for } \\
\text { Course } \\
\text { Additions }\end{array}$ & Priority \\
\hline $\mathbf{1}$ & 3.48 & & - \\
\hline $\mathbf{2}$ & 5.67 & $\mathrm{EL}, \mathrm{CP}$ & 4 \\
\hline $\mathbf{3}$ & 2.95 & $\mathrm{EL}$ & 2 \\
\hline $\mathbf{4}$ & 2.76 & $\mathrm{EL}$ & 1 \\
\hline $\mathbf{5}$ & 5.54 & $\mathrm{OI}, \mathrm{EL}$ & 3 \\
\hline $\mathbf{6}$ & 12.72 & $\mathrm{AEF}, \mathrm{MM}$ & 5 \\
\hline
\end{tabular}

A decision rule to select deletions to the course offering plan for the upcoming term based on projected cost overrun ( $P C O$ in Table 15) is shown in Table 17. $P C O$ varies depending on the cost performance of each cohort. We can make decisions about course deletions in the upcoming term by prioritizing the cohorts in descending order of $P C O$. Ignoring Cohort 1 (as explained previously), the remaining cohorts are prioritized according to decreasing $P C O$ as: Cohort 6 - Cohort 2 - Cohort 5 - Cohort 4 - Cohort 3. Then, based on Figure 2, courses for deletion from the next term $(\mathrm{J}+1)$ should be considered in the following order of program components: AEF, MM (for Cohort 6); EL, CP (for Cohort 2); OI, EL (for Cohort 5); EL (for Cohort 4); EL (for Cohort 3).

Table 17 Prioritizing cohorts (based on PCO) for course deletions in upcoming term

\begin{tabular}{cccc}
\hline Cohort & $\begin{array}{c}\text { Projected Cost } \\
\text { Overrun (PCO) }\end{array}$ & $\begin{array}{c}\text { Candidates for } \\
\text { Course } \\
\text { Deletions }\end{array}$ & Priority \\
\hline $\mathbf{1}$ & $\$ 74,520$ & & - \\
\hline $\mathbf{2}$ & $\$ 224,534$ & $\mathrm{EL}, \mathrm{CP}$ & 2 \\
\hline $\mathbf{3}$ & $\$ 119,273$ & $\mathrm{EL}$ & 5 \\
\hline $\mathbf{4}$ & $\$ 158,595$ & $\mathrm{EL}$ & 4 \\
\hline $\mathbf{5}$ & $\$ 204,911$ & $\mathrm{Ol}, \mathrm{EL}$ & 3 \\
\hline $\mathbf{6}$ & $\$ 421,200$ & $\mathrm{AEF}, \mathrm{MM}$ & 1 \\
\hline
\end{tabular}

The action of adding courses to increase choice of courses and thereby (possibly) reducing average time for graduation is analogous to expediting in conventional projects. On the other hand, the action of deleting courses to decrease cost could have the opposite effect (analogous to de-expediting projects) of increasing average time for graduation. Using the above approach, a program administrator can suitably adjust a long-range course plan by dynamically updating the course offerings for the upcoming term based on the cost and schedule progress made up to that point by the various active cohorts.

The proposed method yields decision rules to select courses to be added to (deleted from) the long-range course offering plan in the near-term, e.g. upcoming semester. Cohorts are prioritized in ascending order of the projected schedule delay (descending order of the projected cost overrun) and courses added (deleted) sequentially by choosing from the program component most applicable to the cohorts in this prioritized order. Since the model only chooses additions/deletions for one term ahead, it should be run on a rolling-horizon basis for each new term with 
updated actual data on each cohort's enrollments during the most recent past term.

To be sure, the number of courses taken each term by a cohort is likely to be variable, and we take this into account by incorporating the actual progress of the cohorts into the model (Table 4). Looking at Cohort 1, for example, we see that these 42 students have taken 58 courses in Term 1, 51 courses in Term 2, and so on. Thus, the average number of courses taken (the "earned" value) is $(58 / 42)=1.38$ and $(51 / 42)=1.21$ in the two terms, respectively. The program has an expected or ideal pace (the "planned" value) which is designated by $E C$ (in $\S 3$ ). It is the differences between the designated planned value for the program and the earned values for the various cohorts that give rise to the project metrics on time and cost. Note also that the model can easily accommodate programs of different size and pace (e.g. graduate vs undergraduate) by setting $E C$ to a suitable value based on the numbers of courses a student in that program typically takes in a term.

\section{CONCLUSION}

In this research, we have demonstrated the use of project management methodology for course planning in educational institutions. Typically, institutions have both long- and short-range plans (schedules) for course offerings in their various programs. A problem commonly faced by program administrators is determining an appropriate mix of courses every term so that students can progress to degree efficiently within the constraints of limited institutional resources.

The project management approach allows a decision maker to consider the twin objectives of minimizing program completion time and maximizing resource utilization. The decision rules proposed here can be used to adjust an existing long-range course plan for the upcoming term. Such an approach is realistic and reasonable in the sense that it explicitly takes into consideration the sizes of the cohorts and their starting terms in evaluating cost and schedule performances. We have approached this problem at an aggregate level (program components such as core, electives, etc.). A possible extension to this work would be to consider the problem at the finer granularity of individual courses. Clearly, any such model will need additional data collection and processing.

\section{ACKNOWLEDGEMENTS}

The work leading to this publication was partially funded by a University of Wisconsin-Whitewater Summer Research Grant.

\section{REFERENCES}

Atkinson, R. (1999). Project management: cost, time and quality, two best guesses and a phenomenon. International Journal of Project Management 17(6), pp. 337-342.

Besent, E.W., and Besent, A.M. (1980). Student flow in a university department: results of a Markov analysis. Interfaces 10(2), pp. 52-59.

Boronico, J. (2000). Quantitative modeling and technology driven departmental course scheduling. Omega 28(3), pp. 327-346.

Cox, J.F., and Jesse, Jr. R.R. (1981). An application of material requirements planning to higher education. Decision Sciences 12(2), pp. 240-260.

Dyson R.G. (2000). Strategy, performance and operational research. Journal of the Operational Research Society 51(1), pp. 5-11.

Gnanendran, K. (2016). Faculty requirements planning and course cycling in part-time, online degree programs. Journal of Business Studies 3(1), pp. 40-49.

Herroelen, W. (2005). Project scheduling - theory and practice Production and Operations Management 14(4), pp. 413-432.

Jacobs, F.R., and Chase, R.B. (2018). Operations and Supply Chain Management, $15^{\text {th }}$ Edition, McGraw Hill Education, New York.

Johnes, J. (2015). Operational research in education. European Journal of Operational Research 243(1), pp. 683-696.

Kavadias, S., and Loch, C. H. (2003). Optimal project sequencing with recourse at a scarce resource. Production and Operations Management 12(4), pp. 433-444.

Kurtulus, I. (1985). Multi-project scheduling: analysis of scheduling strategies under unequal delay penalties. Journal of Operations Management 5(3), pp. 291-303.

Kurtulus, I.S., and Davis, E. W. (1982). Multi-project scheduling: categorization of heuristic rules performance. Management Science 28(2), pp. 161-172.

Kurtulus, I.S., and Narula, S.C. (1985). Multi-project scheduling: analysis of project performance. IIE Transactions 17(1), pp. $58-66$.

Kwak, N.K., Brown, R., and Scheiderjans, M.J. (1986). A Markov analysis of estimating student enrollment transition in a trimester institution. Socio-Economic Planning Sciences 20(5), pp. 311-318.

Litteral, L.A., and Walk, E.M. (2010). The application of Little's Law to enrollment management: improving student persistence in part-time degree programs. Palmetto Business and Economic Review 13, pp. 38-52.

Little, J.D.C. (1961). A proof of the queuing formula $\mathrm{L}=\lambda \mathrm{W}$. Operations Research 9, pp. 383-387.

Lova, A., Maroto, C., and Tormos, P. (2000). A multicriteria heuristic method to improve resource allocation in multiproject scheduling. European Journal of Operational Research 127(2), pp. 408-424.

Mayston, D.J. (2003). Measuring and managing educational performance. Journal of the Operational Research Society 54(7), pp. 679-691.

Nasholm, M.H., and Blomquist, T. (2015). Co-creation as a strategy for program management. International Journal of Managing Projects in Business 8(1), pp. 58-73.

Payne, J.H. (1995). Management of multiple simultaneous projects: A state of the art review. International Journal of Project Management 13(1), pp. 163-168.

Prahalad, C.K., and Ramaswamy, V. (2004). The Future of Competition: Co-creating Unique Value with Customers, Harvard Business Review Press, Boston.

Saltzman, R. M., and Roeder, T.M. (2012). Simulating student flow through a college of business for policy and structural change analysis. Journal of the Operational Research Society 63(4), pp. 511-523.

Manohar Madan is a Professor in the Information Technology and Supply Chain Management Department in the College of Business and Economics at the University of Wisconsin-Whitewater. His teaching and research interests are in the area of Operations and Supply Chain Management. He has a Ph.D. in Operations Management from the University of Tennessee. Manohar's research has been published in many professional journals such as the Journal of Operations Management, IIE Transactions, OMEGA, International Journal of Operations and Production Management, International Journal of 
Production Research and the Journal of Operational Research Society. He is member of APICS and certified as CPIM by APICS.

Kingsley Gnanendran is professor of operations management and director of the online MBA program at the University of Scranton. He earned a B.S. in mechanical engineering from the University of Sri Lanka, M. Eng. in industrial engineering and management from the Asian Institute of Technology, Bangkok, and Ph.D. in management science from the University of Tennessee-Knoxville. His research publications have appeared in: Decision Support Systems, International Journal of Production Research, European Journal of Operational Research, and International Journal of Production Economics. Dr. Gnanendran has been a visiting professor at the University of Waterloo (Ontario, Canada), Capital University of Economics and Business (Beijing), and National Yunlin University of Science and Technology (Taiwan). 